\title{
Memoria de la ciudadanía: preservación de archivos de movimientos sociales y movilizaciones ciudadanas
}

\author{
Citizenship memory: preservation of archives and \\ records of social movements and citizen \\ mobilizations in Spain
}

\author{
Remei Perpinyá-Morera; Pilar Cid-Leal
}

Cómo citar este artículo:

Perpinyà-Morera, Remei; Cid-Leal, Pilar (2020). “Memoria de la ciudadanía: preservación de archivos de movimientos sociales y movilizaciones ciudadanas". Profesional de la información, v. 29, n. 6, e290610.

https://doi.org/10.3145/epi.2020.nov.10

Artículo recibido el 12-02-2020

Aceptación definitiva: 15-06-2020

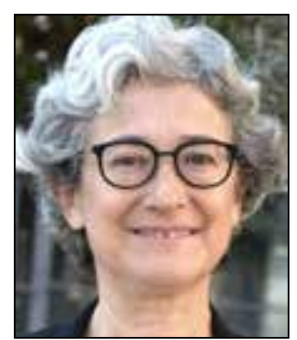

\begin{abstract}
Remei Perpinyá-Morera $₫$ http://orcid.org/0000-0003-4800-6690

Universitat Autònoma de Barcelona Escola d'Arxivistica i Gestió de Documents Edifici blanc, Campus UAB 08193 Bellaterra (Barcelona), España remei.perpinya@uab.cat
\end{abstract}

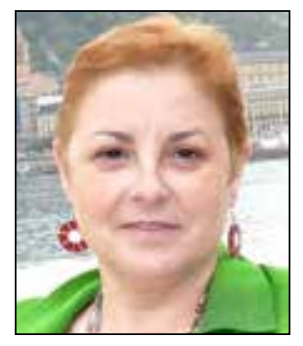

Pilar Cid-Leal http://orcid.org/0000-0001-9820-7541

Universitat Autònoma de Barcelona Facultad de Traducción y de Interpretación Edifici K, Campus UAB. 08193 Bellaterra (Barcelona), España pilar.cid@uab.cat

\section{Resumen}

Se analizan las estrategias de archivado de cinco movilizaciones ciudadanas relevantes acaecidas en España desde 2004. Estas comparten la voluntad explícita de los protagonistas de archivar los documentos generados durante los acontecimientos, para construir así un relato de lo sucedido "desde abajo" y de esta manera ejercer el reconocimiento de sus intereses y derechos. El artículo estudia por qué cada agrupación de documentos constituye un fondo documental; cual es la implicación de la ciudadanía en su configuración; y qué respuesta han dado las instituciones archivísticas para su conservación y custodia. También constata el deseo de los ciudadanos de dejar su huella documental y de utilizar el archivo como un instrumento de empoderamiento. Se argumenta la necesidad de una mayor implicación de los archivos públicos, como instituciones de confianza para custodiar estos fondos producidos por la ciudadanía.

\section{Palabras clave}

Ciudadanía; Archivos; Archivos de la comunidad; Archivos públicos; Archiveros; Movilizaciones ciudadanas; Movimientos sociales; Preservación de documentos; Memoria; Movimiento 15M; Referéndum 1-O; Atentado 11M; Atentados $17 \mathrm{~A}$.

\begin{abstract}
We analyzed the archiving strategies of five citizen mobilizations that have taken place in Spain since 2004. All of them have in common an explicit will of the protagonists to keep the records generated during the events, in order to build an account of what happened "from below" and to achieve recognition of their interests and rights. In this article, we analyze why each group of documents constitutes an archival fonds, the involvement of citizens in its configuration (capture, management, preservation, and dissemination of information), and the response of archival institutions for its preservation and custody. We confirm that citizens want to leave their documentary trace and use archives as a weapon of empowerment. We argue the need for greater involvement of trustworthy public archival institutions to safeguard, beyond the institutional memory, records created by citizens.
\end{abstract}

\section{Keywords}

Citizenship; Archives; Community archives; Archival public institutions; Archivists; Citizen mobilizations; Social movements; Preservation of records; Memory; Movement 15M; Referendum 1-0; Terrorist attack 11M; Terrorist attacks 17A. 


\section{Introducción}

Este artículo describe y analiza las experiencias de archivado derivadas de cinco importantes movilizaciones ciudadanas acaecidas en España desde 2004. Nos referimos por una parte a dos movimientos de protesta:

- el Movimiento 15M o de los Indignados (en referencia al ciclo de manifestaciones y acampadas del 15 de mayo de 2011);

- el movimiento en torno al "Referéndum" del 1 de octubre de 2017 en Cataluña (1-O).

Por otra parte, dos respuestas de duelo ciudadano ante sendos atentados terroristas:

- el del 11 de marzo de 2004 en Madrid (11M);

- el del 17 de agosto de 2017 en Barcelona (17A).

Finalmente, se ha incluido la campaña de denuncia contra la violencia machista llevada a cabo en Twitter bajo el hashtag \#Cuéntalo, entre abril y mayo de 2018.

Estas experiencias plantean cuestiones archivísticas que revisten interés, en la medida que son homologables a otras experiencias internacionales que evidencian la intención de la ciudadanía de dejar constancia de sus actividades para que transciendan. En ellas hay una voluntad explícita de archivar para construir un relato de lo acontecido desde abajo, de conservar los documentos para que se puedan utilizar con posterioridad. Se advierte también una incipiente respuesta favorable de los archivos y los archiveros para ofrecer una solución y preservar en los archivos una memoria diversa y plural, marcada por las tecnologías y con mayor atención a las demandas sociales.

Tradicionalmente los archivos han custodiado los fondos y documentos provenientes de las administraciones públicas y de las instituciones convirtiéndose de facto en los garantes de la memoria institucional. Para Cook (2010, p. 154) el archivo es el reflejo de las instituciones que tuvieron el poder, la motivación y los recursos para conservar sus documentos, hecho que redundó en el mantenimiento de su hegemonía. En Europa, los manuales clásicos de archivística fueron escritos por profesionales de los archivos nacionales, por lo que se centraban en documentos gubernamentales, públicos o institucionales, lo que sin duda privilegió la narrativa oficial de los Estados. Los historiadores y eruditos basaban el estudio del pasado en dichas fuentes oficiales. A la vez, los tipos y soportes documentales eran más limitados que en la actualidad, y el volumen de documentos mucho menor.

La visión actual de los archivos, influida por el postmodernismo, trasciende este marco institucional y asume un compromiso con la sociedad para conservar una memoria plural, reflejo de la diversidad social y comunitaria, tal y como han destacado entre otros los archiveros Cook (2013), Ketelaar (2012) o Harris (2011).

"Los archivos custodian decisiones, actuaciones y memoria" (ICA, 2010).

No sólo conservan evidencias que son testimonio de las decisiones y las actividades de las organizaciones y de las personas, sino también preservan y conforman la memoria individual y colectiva. Los archivos ya no se perciben como objetivos ni neutrales, sino como construcciones sociales que conservan una determinada narrativa del pasado: cada sociedad determina qué vestigios son importantes para conservar. En este sentido Pierre Nora califica a los archivos como uno de los objetos simbólicos de nuestra memoria.

"Los lugares de memoria nacen y viven del sentimiento de que no hay una memoria espontánea, que hace falta crear los archivos, que hace falta mantener los aniversarios, organizar las celebraciones, pronunciar los elogios fúnebres, notariar las actas, parece que estas operaciones no son naturales" (Nora, 1984, p. XXIV).

Estos cambios en los paradigmas archivísticos se producen en un marco social más general: desde hace décadas los ciudadanos se sienten protagonistas, creen que sus actuaciones tienen valor testimonial e histórico y además disponen de las tecnologías adecuadas para documentarlas y compartirlas. El origen de estos cambios hay que buscarlos en las tragedias del siglo XX, que contribuyeron en gran medida a democratizar la historia. El hombre comenzó a sentir que lo que vivía era la historia, contrariamente a lo que sucedía en las sociedades campesinas tradicionales (Corradini, 2006).

Desde finales del siglo pasado hay una obsesión por el archivo y este se halla en el centro del debate cultural (Antich, 2011). La centralidad que adquiere el concepto se inicia con la publicación de Mal d'Archive de Jacques Derrida (traducida al inglés como Archive fever). Para Derrida el concepto Archivación es el momento en qué se decide registrar algo en un soporte y para él

"la archivación produce, tanto como registra, el acontecimiento" (Derrida, 1997).

Paul Ricoeur denomina el diálogo entre el archivo y el acontecimiento como la "puesta en archivo", y

"antes del archivo consultado, constituido, existe la configuración del archivo, la puesta en archivo" (Ricoeur, 2004, p. 215). 
El archivo se presenta así como un

"lugar físico que aloja el destino de esta especie de huella que, con todo cuidado, nosotros distinguimos de la huella cerebral y de la huella afectiva, es decir, la huella documental. Pero el archivo no es sólo un lugar físico, espacial; es también un lugar social” (Ricoeur, 2004, pp. 216-217).

Eric Ketelaar (2001, p. 133) retoma esta idea y usa el término Archivalization que define como la elección consciente o inconsciente (determinada por factores sociales y culturales) para considerar que una cosa tiene el valor de ser archivable. La decisión de reunir y conservar los documentos por las manifestaciones ciudadanas analizadas en este artículo se corresponde con el concepto de archivalización de Ketelaar, de forma que desaparece la brecha entre el acontecimiento y su registro porque el propio protagonista es narrador y archivero a la vez.

En suma, el debate del postcustodialismo en los archivos deja claro que los documentos son esenciales para construir una comunidad, consolidar su identidad y moldear su memoria (Bastian; Alexander, 2009). En la última década ha surgido con fuerza el concepto "archivos de la comunidad" (community archives), que se refiere a

"Las (a menudo) actividades básicas de crear y recopilar, procesar y curar, preservar y hacer accesibles colecciones sobre con una comunidad en particular o un tema específico" (Flinn, 2007, pp. 152-154).

Si bien inicialmente el término hacía referencia a iniciativas para la custodia de archivos de la diversidad étnica o racial, en la actualidad se ha ampliado el uso del concepto, que se extiende a proyectos variados que pivotan alrededor de las identidades de la comunidad y el reconocimiento de derechos. Se pueden citar como ejemplos:

- la custodia de la comunidad aborigen en Australia (Kelly, 2009);

- las comisiones de la verdad y la construcción de la memoria colectiva en Chile (Blanco-Rivera, 2009);

- los archivos no oficiales en Colombia (Giraldo, 2019);

- los archivos queer en California (Wakimoto; Bruce; Partridge, 2013).

Todos estos proyectos tienen en común la idea de fomentar el archivo multiverso (Gilliland; McKemmish; Lau, 2016). Una característica definitoria de los archivos de la comunidad es

"la participación activa de una comunidad para documentar y hacer accesible la historia de su grupo particular y/o localidad en sus propios términos" (Flinn; Stevens; Shepherd, 2009, p. 73).

En definitiva, se trata de lo que Evans et al. (2015) denominan la autonomía de archivo, que definen como la capacidad de los individuos y de las comunidades de participar en la memoria social con su propia voz.

En este nuevo contexto, se considera que los archiveros deben tener un papel crucial para potenciar la construcción de la memoria plural. Verne Harris, que ha estudiado los archivos en el contexto de la transición del apartheid a la democracia en Sudáfrica, interpela al activismo de los archiveros para abrir los archivos "to the alien, strangers" y recuperar la memoria y las historias suprimidas por el poder (Harris, 2002, p. 104). Además, se debe favorecer la participación de los ciudadanos en la toma de decisiones sobre qué memoria se debe conservar. En palabras de Cook

“En este nuevo universo digital, político y plural, los archiveros profesionales necesitan transformarse, de expertos de élite tras los muros institucionales, a mentores, facilitadores, entrenadores, que trabajan en la comunidad para fomentar el archivo como un proceso participativo compartido con muchos en la sociedad, en lugar de adquirir necesariamente todos los productos de archivo en nuestros archivos establecidos" (Cook, 2013, p. 114).

De hecho, la asociación Archiveros sin Fronteras, creada en Cataluña en 1998 y actualmente con presencia en Argentina, Perú, Bolivia, Brasil, Uruguay, Colombia, México, Chile, Ecuador y Francia, ya inició ese camino activista en la conservación de fondos y documentos esenciales para la lucha por los derechos humanos en distintos proyectos y territorios, como por ejemplo en la recuperación del Archivo Histórico de la Policía en Guatemala, o la cooperación con el tratamiento de la documentación del Pueblo Saharaui (Alberch-Fugueras, 2000; Corominas-Noguera, 2005).

http://www.arxivers.org/home/es-es/qui-som-2/asf-internacional

Evans et al. (2015) abogan para que este tipo de activismo archivístico vaya más allá de fomentar una mayor diversidad en los fondos de archivos para transformar la forma en que los sistemas de gestión de documentos y de archivo se conectan con el tejido social e impulsen la justicia social y los derechos humanos.

\section{Objetivos y metodología}

Como se ha visto, existe una abundante literatura internacional sobre archivos de la comunidad y activismo archivístico. En cambio, en España no existen análisis de experiencias similares. El presente artículo estudia las iniciativas de archivado derivadas de las cinco importantes movilizaciones ciudadanas espontáneas antes mencionadas acaecidas desde
Los archiveros deben tener un papel crucial para potenciar la construcción de la memoria plural 
2004, y que ejemplifican cómo también en España se llevan a cabo iniciativas donde la ciudadanía, al margen o en colaboración con las instituciones archivísticas, se autoorganiza para constituir sus propios fondos.

Para lograr este objetivo general, planteamos los siguientes objetivos específicos:

- Analizar y describir las características de cada caso (contexto, productor, formación del fondo y conservación).

- Considerar las implicaciones que estos fondos plantean en relación con la teoría y la práctica archivística tradicional.

- Reflexionar sobre el papel de las instituciones de archivo para conservarlos y custodiarlos.

La metodología de trabajo utilizada es de carácter cualitativo. Se han seleccionado cinco experiencias significativas por su relevancia social:

- las derivadas de dos movimientos sociales ${ }^{1}$ (15M y Referéndum 1-0) que por motivos diferentes han reconfigurado la política española;

- dos manifestaciones de solidaridad y duelo (Madrid 11M y Barcelona 17A), cuyo origen fueron sendos atentados obra del islamismo radical y que conmovieron profundamente a la sociedad española;

- la campaña de movilización y denuncia en Twitter \#Cuéntalo; posiblemente es el testimonio más directo y extenso en cuanto a violencia machista se refiere y refleja un cambio de mentalidad que propicia la denuncia sin paliativos.

Se han escogido estos casos porque, pese a sus especificidades, comparten características que permiten un análisis comparativo:

- De cada uno de estos movimientos ha surgido un archivo.

- En todas las iniciativas los protagonistas de las movilizaciones han querido conservar la memoria de lo sucedido a partir de diferentes estrategias de recogida, conservación y difusión.

- Las movilizaciones que originan estos archivos han sido acontecimientos espontáneos, surgidos de abajo hacia arriba y que expresan protesta e indignación.

- Todos ellos tienen una manifestación física en la calle y virtual en las redes. Producen materiales muy variados: pueden ser documentos de carácter operativo (por ejemplo, comunicados), testimoniales (fotografías, tweets) o simbólicos (objetos dejados en los altares de memoria), en cualquier forma y soporte, además de los miles de mensajes enviados a través de las redes sociales (Facebook, Twitter, YouTube, Instagram, etc.).

De cada caso se describe brevemente el acontecimiento que ha dado origen al archivo, cómo se constituyó éste, su objetivo, composición, difusión y uso. Para la recopilación de datos se han utilizado tres instrumentos:

- publicaciones de las personas y entidades vinculadas a los procesos de archivado; en ellos encontramos con voz propia el relato de los acontecimientos, la justificación de las decisiones tomadas y los debates y reflexiones que surgieron;

- revisión de los inventarios publicados en las páginas web;

- conversaciones con algunos de los protagonistas para complementar o confirmar datos.

El enfoque cualitativo resulta especialmente adecuado para estudiar acciones y procesos como los expuestos aquí, que han sido impulsados por ciudadanos individuales, de forma espontánea en sus comienzos, y que todavía no están cerrados.

En el apartado de resultados y discusión constatamos las particularidades de estos fondos y reflexionamos sobre las implicaciones que plantean en relación con la teoría y la práctica archivística tradicional. En este sentido:

- identificamos la procedencia y el productor y argumentamos por qué el conjunto de documentos generados constituye un fondo documental;

- analizamos la formación de los fondos y corroboramos la voluntad explícita de archivar;

- planteamos la dificultad de asegurar el valor evidencial y la autenticidad de una documentación heterogénea;

- abordamos la implicación de las instituciones archivísticas y de los profesionales de archivo en su custodia.

\section{Descripción de los casos}

\subsection{Archivo del duelo}

El 11 de marzo de 2004 un grupo yihadista perpetró un atentado terrorista en cuatro trenes de la red de cercanías de Madrid, con un balance de casi 200 personas fallecidas y alrededor de 1.800 heridas.

La ciudadanía, conmocionada, respondió rápidamente con una serie de iniciativas anónimas y espontáneas. Conscientes de la importancia de esas manifestaciones, investigadores del Consejo Superior de Investigaciones Científicas (CSIC) iniciaron un proyecto de investigación multidisciplinar que tenía como objetivo catalogar y estudiar la multitud de materiales depositados en los altares improvisados instalados en algunas estaciones ferroviarias y que por su naturaleza estaban destinados a ser efímeros. Nacía así el Archivo del Duelo.

Criado-Boada, coordinador del Área de Humanidades y Ciencias Sociales del CSIC, resaltaba la singularidad del Archivo del Duelo, porque no es un archivo de los atentados del $11 \mathrm{M}$, sino una

"colección activa que refleja la respuesta social al dolor producido por los atentados" y está constituido por "los objetos, los materiales, las piezas que espontánea y activamente reflejaron el dolor de nuestra sociedad ante el 11M" (Criado-Boada, 2005, p. 1). 
En una primera fase, los antropólogos documentaron con fotografías, grabaciones y vídeos lo que estaba sucediendo en las estaciones. Meses más tarde el CSIC firmó un convenio con Renfe, que donaba los materiales recogidos en los altares para que fuesen ordenados, estudiados y conservados

"en un entorno académico y sin ningún condicionamiento interesado" (Cea et al., 2011, p. 50).

La colección documental y bibliográfica resultante fue de 2.482 fotografías, 495 objetos, 6.432 papeles, 58.732 emails y 84 grabaciones (Cea et al., 2011, p. 52). En 2005 se elaboró el cuadro de clasificación, que permitiría una descripción multinivel; entre 2005 y el 2008 se catalogó y clasificó siguiendo las pautas técnicas del sistema bibliotecario del CSIC. En la creación de la colección y el complejo procesamiento técnico del fondo, dada la enorme variedad de soportes y tipologías y los diferentes estados de conservación, intervino un equipo profesional multidisciplinar (Martínez, 2011, p. 71), y hubo una colaboración estrecha entre el personal científico y los técnicos de bibliotecas, archivos y museos del CSIC.

Una vez organizada y digitalizada la colección, en 2010 fue cedida junto a las bases de datos que la acompañaban al Archivo Histórico Ferroviario de la Fundación de los Ferrocarriles Españoles, donde permanece en estos momentos.

El Archivo del Duelo no permite el libre acceso a los materiales; sólo pueden consultarse con una autorización previa. Incluso el cuadro de clasificación no es visible en la web, por lo que el usuario no puede tener una idea del contenido exacto de la colección hasta que, por ejemplo, recibe por correo dicho cuadro (al menos, esa es la experiencia de las autoras). La institución considera que el acceso y uso debe estar restringido dada la naturaleza sensible que se recoge y por los datos personales que contiene.

\subsection{Archivo $15 M$}

El 15M, también conocido como Movimiento de los indignados (a partir del ensayo Indignez-vous! de Stéphane Hessel) entre otras denominaciones, es un movimiento ciudadano surgido de la indignación popular que eclosionó tras las manifestaciones del 15 de mayo de 2011 en más de 50 ciudades españolas.

A raíz de las movilizaciones surgieron diversas iniciativas para recopilar y preservar el alud de información que se generaba y difundía. Una gran parte ha desaparecido con el tiempo y las webs no están operativas. Incluso un número indeterminado de vídeos que se subieron a YouTube ya no se encuentran. Otras iniciativas han perdurado, como son el fondo Acampada Terrassa 15M (acumulado por las organizaciones \#Acampadatrs, Moviment 15M de Terrassa y iDemocracia Real Ya! de Terrassa y depositado en el Archivo Comarcal del Vallés Occidental en Cataluña). También es el caso del Archivo 15M de Acampada Sol, que tuvo lugar en la Puerta del Sol de Madrid y que describimos a continuación por ser el más representativo del movimiento.

La Comisión del Archivo 15M de Acampada Sol nació a los pocos días de iniciarse las acampadas de 2011. Ante la cantidad de información que se estaba generando y circulando por internet y conscientes de su importancia testimonial, un grupo de personas se planteó recopilarla y conservarla. Ello prueba que los manifestantes entendían que protagonizaban un "momento histórico" y se preocuparon por documentarlo (Senante, 2012).

La recopilación de materiales físicos y digitales tuvo lugar a partir de donaciones individuales y de las comisiones en las que se organizó el movimiento. Sin apenas medios y en plena movilización general, los voluntarios recogieron toda clase de materiales en los soportes más heterogéneos. Asimismo, la Comisión tenía la

“intención quimérica de poder capturar la información de la web relacionada con el 15M" (Archivo 15M, 2014),

por lo que mantuvieron contactos con Internet Archive.

La preservación de estos fondos ha sido azarosa; una de las principales dificultades fue la ausencia de un local permanente y seguro, por lo que durante años fue un archivo nómada, hasta que se depositó en su actual sede, el Centro Social Tres Peces Tres (Madrid).

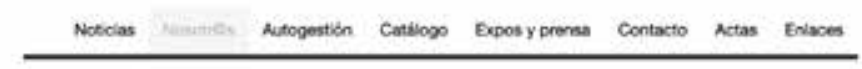

\section{Archivo I5M}
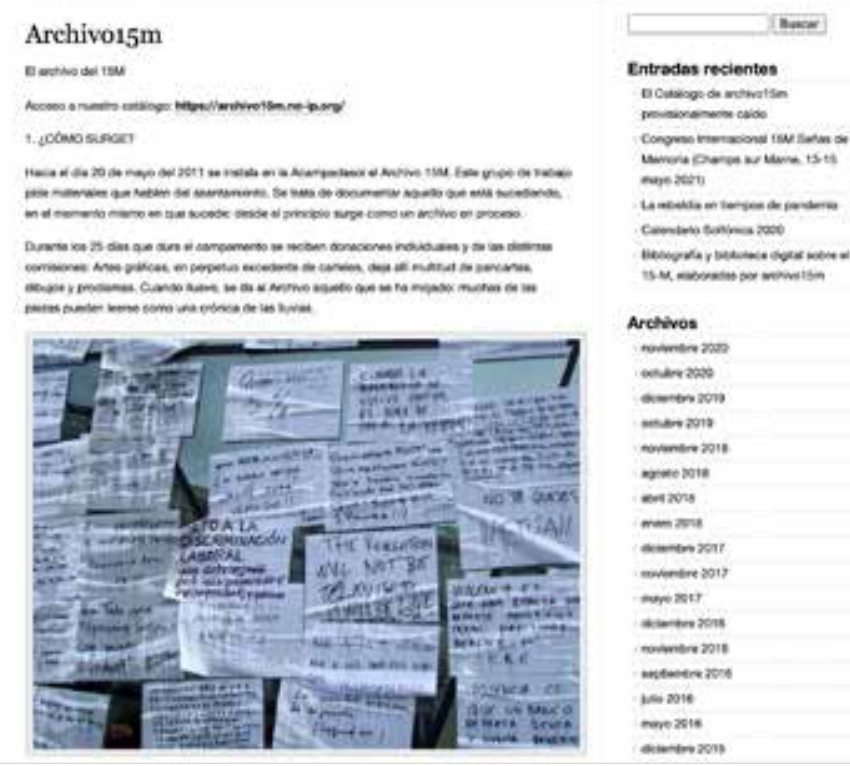

https://archivosol15m.wordpress.com/about 
El objetivo del Archivo es preservar y difundir los documentos de Acampada Sol y no perder la memoria del movimiento (Archivo 15M, 2018) para poder interpretar sus claves históricas y políticas. Pretende conformar así un archivo que recoja la voz colectiva de la sociedad.

El fondo actual está integrado por los materiales más significativos de la acampada de la Puerta del Sol: audiovisuales, fotografías, carteles y pancartas, panfletos, convocatorias, actas de asambleas, dibujos, cartas, poemas, mapas, prensa y objetos de índole diversa. Todo ello en una multitud de soportes y formatos heterogéneos (por ejemplo, desde post-its a pancartas de varios metros). El fondo sigue incrementándose con nuevas donaciones.

El archivo recopila, clasifica, conserva, restaura en la medida de lo posible y digitaliza todo tipo de materiales. El catálogo online da acceso a diversas colecciones y series. Se ha confeccionado con ICA-AtoM, software libre que utiliza los estándares del Consejo Internacional de Archivos. Los documentos disponibles en la web tienen licencia Creative commons: puede utilizarse libremente, citando la autoría y la fuente, sin fines comerciales y ofreciendo las obras derivadas en las mismas condiciones.

http://archivo15m.no-ip.org

El Archivo $15 \mathrm{M}$ es un proyecto solidario, autofinanciado y autogestionado. Ha podido salir adelante gracias a la colaboración desinteresada de voluntarios, entre los que se cuentan archiveros, documentalistas, bibliotecarios, fotógrafos o diseñadores, que con su trabajo

“cotidianamente reformulan la propia noción de lo que es un archivo" (Archivo 15M, 2018).

Los fondos han sido utilizados para realizar un amplio abanico de actividades propias: exposiciones, actos reivindicativos, publicaciones, etc. Pero también se han prestado para las de otros colectivos, incluso en el extranjero. Sumamente activo, en estos momentos el Archivo 15M elabora una bibliografía y biblioteca digital sobre el movimiento, que reúne documentos de múltiples procedencias (Archivo 15M, 2019).

El archivo

"decidió no aceptar dudosas propuestas institucionales que garantizarían su futuro, seguramente enterrado en algún sótano en espera de una futura resurrección académica, y apostó temerariamente por mantenerse vivo desde una asamblea con escasos recursos, pero fiel al movimiento que lo generó, mientras parecíamos renunciar al futuro, en realidad lo que hacíamos era no convertirlo en pasado, manteniéndolo en el presente" (Archivo $15 M, 2015$, pp. 146-147).

Este planteamiento pone de relieve la importante brecha que existe entre ciudadanos y archivos, en la medida que refleja como estos últimos son percibidos en términos peyorativos: una suerte de almacén en el que los fondos depositados extinguen su proyección pública.

\subsection{Memorial La Rambla 17A}

El 17 de agosto de 2017 se produjeron dos ataques terroristas yihadistas en Catalunya:

- el primero ocurrió en el centro de Barcelona, donde una furgoneta arrolló a los peatones que transitaban por Las Ramblas;

- el segundo ocurrió en el paseo marítimo de Cambrils (Tarragona). En total murieron dieciséis personas y más de cien resultaron heridas.

A lo largo de los días siguientes la ciudadanía, conmovida por el horror, dejó espontáneamente en Las Ramblas numerosas muestras de duelo y apoyo a las víctimas y a sus familiares y de rechazo al terrorismo. El 26 de agosto se convocó una manifestación para condenar el terrorismo con el lema "No tinc por" (No tengo miedo) a la que asistieron medio millón de personas.

El Ayuntamiento de Barcelona reaccionó con rapidez y determinó que los testimonios de duelo de los ciudadanos debían recogerse y conservarse para que no fuera simplemente un espacio de duelo efímero. Se contabilizaron hasta 130 espacios con objetos memoriales que se retiraron entre el 27 y el 2 de agosto para su posterior tratamiento y conservación gracias a un proyecto conjunto entre el Museo de Historia de Barcelona (MUHBA) y el Archivo Municipal Contemporáneo de Barcelona $(A M C B)$.

Además el Ayuntamiento, de forma proactiva documentó gráficamente y con reportajes audiovisuales dichos objetos memoriales. Siguiendo el protocolo técnico, se retiró el material, se anotó la procedencia de cada pieza, se agrupó en cajas separando los documentos escritos del resto de objetos, los cuales se depositaron en las dependencias del $A M C B$ y del MUHBA para recibir el tratamiento más adecuado en cada caso siguiendo los criterios archivísticos y museográficos.

Un año después, y gracias al convenio de colaboración firmado entre el Ayuntamiento y la Fundación Telefónica, se activó la web Memorial la Rambla 17A (Ajuntament de Barcelona, 2017) que muestra más de 12.000 documentos y objetos 
digitalizados y algunos transcritos y da a conocer las cifras de las muestras de duelo expresadas por los ciudadanos. Los documentos textuales están inventariados, digitalizados y debidamente conservados en el $A M C B$. También los objetos recogidos en Las Ramblas se catalogan en el MUHBA; falta decidir qué parte se conservará y que parte formará parte de las colecciones del museo.

El fondo del Memorial de La Rambla conservado en el $A M C B$ está compuesto por los siguientes elementos:

- documentos escritos que se recuperaron de los espacios memoriales;

- libros de condolencia que el Ayuntamiento puso a disposición de instituciones, autoridades, personas implicadas en el atentado y la ciudadanía en general;

- documentos diversos como cartas, versos, postales y carteles que personas particulares hicieron llegar al Ayuntamiento.

Constituyen un conjunto de testimonios sobre la respuesta ciudadana a los atentados.

De esta experiencia cabe destacar tres aspectos:

- la rapidez con la que reaccionó el Ayuntamiento y sus técnicos;

- la colaboración entre el museo y el archivo municipales;

- la colaboración financiera de Fundación Telefónica.

Los ciudadanos también expresaron la indignación y las condolencias a partir de las redes sociales. La Associació d'Arxivers-Gestors de Documents de Catalunya $(A A C-G D)$ se encargó de recoger los tweets que incorporaban la etiqueta \#Notincpor, y preservarlos con la aplicación Documenting the Now. Se ha preservado un conjunto de datos de 52.808 tweets que se publicaron en Twitter con el hashtag \#NoTincPor entre el 17 y el 26 de agosto de 2017, disponible en la web del catálogo de DocNow.

https://www.docnow.io/catalog

\section{4. \#arxivemelmoment: 1 de octubre de 2017 en Cataluña}

Los resultados de las elecciones autonómicas del 27 de septiembre de 2015 en Cataluña conformaron una mayoría parlamentaria independentista con la suma de los diputados de la coalición JuntsxSí y de la Candidatura d'Unitat Popular (CUP). En enero de 2016 Carles Puigdemont, diputado de JuntsxSí, fue elegido presidente con el objetivo de llevar a Cataluña a la independencia. Ello se materializó en la decisión de organizar un referéndum con esta pregunta:

“¿Quiere que Cataluña sea un Estado independiente en forma de República?”

La convocatoria del referéndum, fijado el 1 de octubre de 2017 (1-0), fue recurrida en los tribunales por parte del gobierno de Mariano Rajoy, que lo declaró ilegal. Para impedir su celebración, el ejecutivo desplegó diversas medidas, como la intervención económica de la Generalitat, el registro del Departamento de Economía de la Generalitat, la inspección de imprentas y sedes de correos y la requisa de urnas y papeletas. A pesar de ello, el día previsto se celebró la consulta sobre la independencia. Los ciudadanos que se implicaron en ella custodiaron las urnas y las sedes de los colegios electorales y la mañana de esa jornada miles de personas hicieron largas colas para votar. Durante el mes previo al referéndum y en los días posteriores al mismo, se llevaron a cabo numerosas protestas ciudadanas públicas reivindicando la libertad de expresión, el derecho a celebrar el plebiscito y condenando la actuación del gobierno central, así como expresando el rechazo a la judicialización del proceso independentista.

En este contexto, la $A A C-G D$ hizo una llamada en su web a ciudadanos y archivos para preservar las evidencias sobre el movimiento social y político que se estaba produciendo. La campaña, denominada \#arxivemelmoment [archivemoselmomento], se inició el 20 de septiembre de 2017, a raíz de la manifestación espontánea que tuvo lugar en la Rambla de Cataluña delante de la sede del Departamento de Economía, para impedir el registro de la Guardia Civil. La AAC-GD publicó consejos básicos para la ciudadanía en relación con cómo salvaguardar los materiales y proporcionó la lista de archivos catalanes (municipales y comarcales) para que los ciudadanos pudieran depositar testimonios documentales en ellos. La $A A C-G D$ también dio una serie de recomendaciones para los archivos y archiveros que se quisieran adherir a la campaña $(A A C-G D, 2017)$ que reforzaba el papel de los archivos como instituciones vinculadas a la ciudadanía. 
Esta llamada a la participación ciudadana no sólo promovía la preservación de testimonios personales (más allá de los oficiales), sino también la integración de las personas en los procesos archivísticos de evaluación para determinar qué documentos se deberían conservar, evitando redundancias. Además, proveía de un protocolo de ingreso de los materiales aportados en los archivos para asegurar la autenticidad y la fiabilidad de los documentos y el respeto a los derechos de autor.

La campaña tuvo mucho éxito entre los archivos públicos, especialmente los comarcales y municipales. La web de la $A A C$ $G D$ cartografía 50 iniciativas de archivos que se sumaron a la campaña de captación de videos, fotografías y documentos (entre ellos 15 comarcales y 25 municipales) (AAC-GD, 2017). El Gobierno de la Generalitat se sumó a la iniciativa con la campaña denominada \#Memòria1oct (Arxiu Nacional de Catalunya, 2017). A finales de 2019 no había un recuento publicado de los documentos llegados a los archivos catalanes.

En paralelo, los archiveros Vicenç Ruiz y Aniol María de la $A A C-G D$, con la colaboración de Ed Summers, preservaron los tweets provenientes de los hashtags \#CatalanReferendum, \#CatalalonianReferendum, \#Catalonia, \#1oct, \#10, y \#votarem, con la tecnología de Documenting the Now. Este conjunto de datos contiene 8.410.431 de tweets capturados entre el 19 de septiembre y el 5 de octubre de 2017 y se encuentra disponible en internet (Ruiz-Gómez; Maria-Vallès; Summers, 2017).

A los proyectos de las entidades archivísticas se sumaron las iniciativas ciudadanas. El 4 de octubre de 2017 surgió un proyecto colaborativo para recoger testimonios del 1 de octubre. Denominado \#catmemoria, sus promotores lo han definido como

"el fruto de vivencias en primera persona; es el fruto de la tristeza, pero también de momentos de alegría; es el resultado de la necesidad de compartir aquellos momentos con todo el mundo, de evitar el olvido y mostrar al mundo lo que pasó en Cataluña durante la jornada del referéndum de autodeterminación” (@catmemoria, 2017).

La web de la $A A C-G D$ acoge aportaciones de los ciudadanos, bibliografía, audiovisuales de los informativos televisivos, declaraciones políticas y otros documentos. Es una visión subjetiva que recoge las vivencias en primera persona durante la jornada del referéndum.

https://arxivers.com/campanyes/arxivar-lavui-per-guardar-el-futur

\section{5. \#Cuéntalo}

El 26 de abril de 2018, la Audiencia Provincial de Navarra hizo pública la sentencia que condenó a nueve años de prisión a cinco hombres juzgados por la violación múltiple a una mujer durante los Sanfermines de 2016. La sentencia no les condenó por violación sino por abuso sexual continuado. Popularmente se conoció como la "Sentencia de la Manada", y provocó una indignación generalizada que se tradujo en manifestaciones de rechazo a la sentencia en todas las ciudades españolas, así como un alud de denuncias en las redes sociales de mujeres que habían sufrido agresiones sexuales.

En este escenario, la periodista Cristina Fallarás publicó el 28 de abril un tweet con el hashtag \#Cuéntalo, haciendo un llamamiento para que las mujeres contaran historias de abusos o acosos sexuales. La respuesta fue un aluvión de aproximadamente tres millones de tweets: 2,6 millones eran retweets, 9.500 retweets con comentarios, 128.400 con contenido propio y 22.500 respuestas (Valdés, 2018). Ante la importancia social que estaba alcanzando este hashtag, los archiveros de la $A A C-G D$, Aniol Maria y Vicenç Ruiz, utilizaron la experiencia adquirida en la captura de hashtags relacionados con el atentado del 17A y con el Referéndum del 1 de octubre para iniciar un proyecto de preservación del dataset que tuvo una duración de dos semanas, entre el 27 de abril y el 13 de mayo de 2018 y que contiene 2.111 .998 tweets en 12,8 GB (Ruiz-Gómez; Maria-Vallès, 2018).

A partir del dataset se inició un proyecto para el análisis y la conservación de los datos con la participación de un equipo multidisciplinar que involucró a las periodistas Karma Peiró y a la propia Fallarás, a los mencionados archiveros Ruiz y Maria y al ingeniero informático Fernando Cuchietti del Centro de Supercomputación de Barcelona. No cabe duda de que este proyecto es de gran trascendencia social, al dar visibilidad y voz a las mujeres que han sufrido violencia machista; y más 
en la medida en que los testimonios son mujeres anónimas sin relevancia pública. El análisis de los datos aporta información sobre asesinatos $(9,8 \%)$, violaciones $(14 \%)$, agresiones sexuales $(28 \%)$, maltrato $(15,7 \%)$, acoso $(35,5 \%)$, o miedo a salir sola de noche, a caminar sola, a llegar tarde a casa (29,5\%) (Millán, 2018).

Este proyecto se encuentra en sus inicios, de modo que no se sabe qué recorrido tendrá ni dónde se conservará. En todo caso ha tenido una gran repercusión en la prensa española y también en los medios profesionales de archivo. Se pueden consultar los primeros resultados en

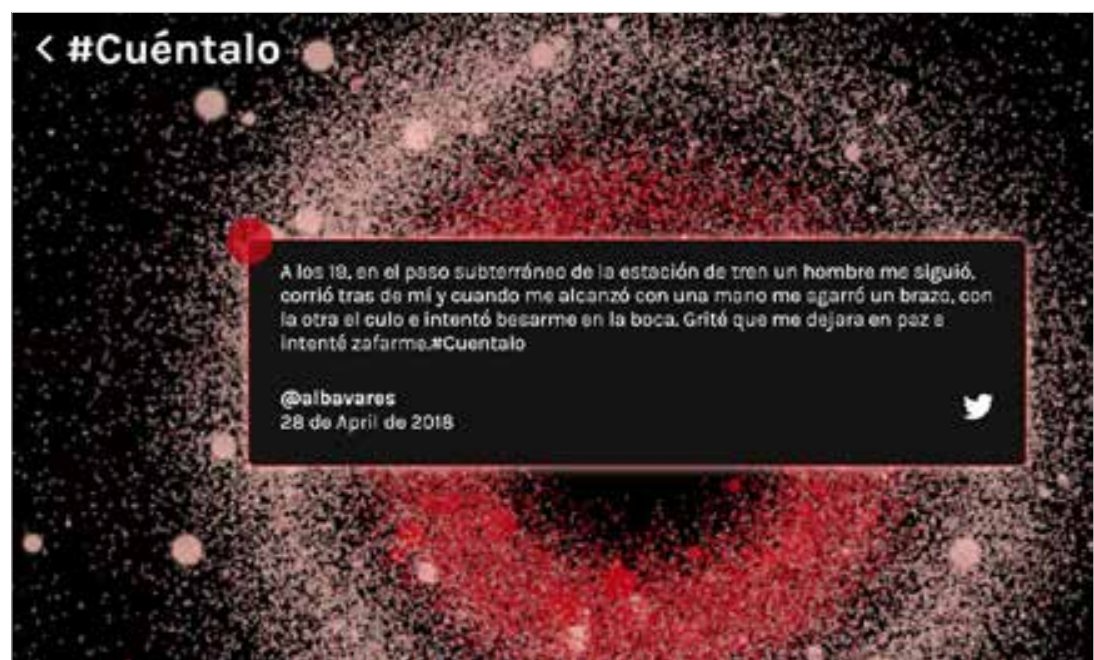

http://www.proyectocuentalo.org la web \#Cuéntalo.

http://www.proyectocuentalo.org

En cualquier caso, estamos ante un claro ejemplo de activismo archivístico desde las asociaciones de archiveros para conservar y diseñar lo que los promotores del proyecto llaman archivo social (Ruiz-Gómez, 2019).

\section{Resultados y discusión}

El análisis de estos casos plantea cuestiones interesantes en cuanto a la teoría y a la práctica archivística, que tratamos a continuación.

\section{1. ¿Son fondos de archivo?}

La primera cuestión es si la documentación de cada movimiento ciudadano constituye un fondo de archivo. La definición clásica indica que un fondo es el

"conjunto de documentos, con independencia de su tipo documental o soporte, producidos orgánicamente y/o acumulados y utilizados por una persona física, familia o entidad en el transcurso de sus actividades y funciones como productor" (ICA, 2000).

Se distingue de la colección en tanto que esta es

"el conjunto artificial de documentos acumulados sobre la base de una característica común sin tener en cuenta su procedencia" (ICA, 2000).

El concepto clave que define un fondo es pues el concepto de productor y el contexto de creación, tal y como ya se formuló en el siglo XIX a partir del principio de procedencia, que en esencia indica que los documentos de una misma procedencia se deben mantener juntos.

Así pues, para identificar un fondo es necesario reconocer un productor, que es el que genera, recibe y conserva los documentos como testimonio de su quehacer. ¿Se puede identificar un productor en los casos estudiados? No cabe duda de que en ellos el concepto clásico de productor orgánico de los fondos queda desdibujado. En ninguno de los casos se puede identificar un organismo único, jurídicamente constituido, que produce documentación e información, sino que en todos los casos el productor es un colectivo. Por una parte, hallamos los que provienen de movimientos sociales, como son el $15 \mathrm{M}$ y el 1-0, que conformaron un colectivo heterogéneo con una agenda política con continuidad en el tiempo. Por otra parte, también constatamos movilizaciones ciudadanas espontáneas de duelo e indignación, de existencia limitada en el tiempo.

La teoría archivística ha ampliado el concepto de procedencia y productor considerando que la visión orgánica es restrictiva. El record continuum incide en que la procedencia de los documentos es multifacetada y se define por la red de relaciones entre las entidades y su contexto de creación (Upward, 1996). Teniendo en cuenta las nuevas formas de organización mutables y distribuidas, se priorizan las consideraciones funcionales a las orgánicas y el fondo se percibe como una abstracción conceptual más que física (Yeo, 2017, p. 167). Nesmith (2006) introduce el término societal provenance e incide en que la creación, uso y conservación de los documentos tienen orígenes sociales y se hace con propósitos sociales.

Conceptos como procedencia múltiple y coproductor, formulados entre otros expertos por Hurley (2005a; 2005b), son muy pertinentes para tratar archivos comunitarios formados por la acumulación de la documentación de diferentes orígenes. Las normas de descripción actuales introducen estas nuevas ideas. El borrador de la versión 0.2 del Records in context: Modelo conceptual de descripción archivística, tiene en cuenta esta visión más amplia del productor y utiliza el concepto 
Group, que define como dos o más agentes (una persona, un grupo o una entidad creada por una persona o un grupo o una posición) que actúan conjuntamente y que tienen una identidad social reconocida (ICA, 2019.) Además, para una comprensión global de la procedencia, junto a la identificación del productor y el contexto social, también es necesario conocer cómo los documentos se han custodiado, transmitido y usado a lo largo del tiempo (Douglas, 2017).

En los casos estudiados no se puede identificar una entidad con una estructura orgánica pero sí que se identifica un colectivo más o menos organizado, con un propósito social compartido. Es por ello que los archivos analizados se pueden considerar, en palabras de Flinn (2007), archivos de la comunidad, en el sentido que cada uno acoge los testimonios y las evidencias de un conjunto de personas vinculadas por unos intereses comunes, que a su vez son conscientes del valor evidencial y testimonial del fondo que producen y custodian, y que se reivindican como voces complementarias al relato institucional de los acontecimientos por parte de las administraciones públicas. Lo que los define como fondo es que se puede identificar un productor colectivo, que comparte unos intereses y una finalidad social y, además, una voluntad de memorializar y conservar sus documentos.

\subsection{Formación de los fondos: génesis natural e intencionalidad}

Los documentos de dichas movilizaciones se han gestado de forma natural en el transcurso de las acciones de los productores, pero esto no ha estado reñido con la realización de un proceso de evaluación desde los propios productores para determinar cuáles se conservan y cuáles no. Tal y como nos recuerda Eastwood (2017, p. 16), tampoco en los archivos de las instituciones se memorializan todas las acciones.

El origen de los archivos descritos es fruto del activismo de ciudadanos y archiveros y de la voluntad de constituir un fondo. En el caso del 15M fueron los protagonistas del movimiento, que incluía a archiveros, los que tomaron la iniciativa de constituir el archivo. En el 1-O se constatan dos iniciativas en paralelo: por un lado, la ciudadana; por otro, la protagonizada por la $A A C-G D$. Esta última constituyó la primera gran campaña llevada a cabo en Cataluña para involucrar a la ciudadanía en la captación de documentos y que además preveía el archivado antes incluso de la celebración del acontecimiento de referencia. También en \#Cuéntalo ha sido esencial ese activismo profesional para la constitución de un archivo, si bien en este caso a partir de un proyecto multidisciplinar formado por archiveros, periodistas e informáticos.

En los tres casos (11M, 17A y \#cuéntalo) son los archiveros los que documentan esas manifestaciones ciudadanas, asumiendo un activismo archivístico que no es ajeno a su implicación política y social en la comunidad en la que viven.

La formación de los archivos del Duelo y del atentado del 17A proviene de iniciativas institucionales. En el primer caso, por el mismo Archivo Histórico Ferroviario de la Fundación de los Ferrocarriles Españoles y el CSIC. Y en el segundo caso por el Ayuntamiento de Barcelona. No obstante, también los dos son fruto de la voluntad de la ciudadanía por dejar constancia documental de su malestar.

El límite del fondo es un convencionalismo. El propio productor colectivo decide registrar y conservar unos determinados acontecimientos y no otros, dentro de unas fechas determinadas. El espacio destinado al archivo constituye el fondo y sus límites. Si la iniciativa parte de los profesionales, como en el caso del 17A, el 1-0 o \#Cuéntalo, son las instituciones archivísticas o los archiveros los que determinan su alcance. De hecho, los fondos no dejan de ser convenciones archivísticas y sin la existencia de un archivo que lo identifica no existirían como tal (Matas-Balaguer, 1999, p. 19).

Aunque con matices distintos, todas las iniciativas tienen como objetivo ofrecer un relato propio de los acontecimientos y de la gente que se involucró en ellos. De hecho, la voluntad de documentar y de archivar es un instrumento más de denuncia junto con las manifestaciones en la calle o los mensajes en Twitter.

\subsection{Composición de los fondos: nuevos documentos, nuevos retos}

La composición de los fondos es heterogénea, con una presencia muy importante de documentos que provienen de las redes sociales. Se recogen documentos que nada o poco tienen que ver con los documentos oficiales tradicionales. Entre otros reúnen escritos (pancartas, murales, panfletos, manifiestos, cartas, canciones), objetos variopintos, gran cantidad de audiovisuales y fotografías. Afloran nuevos documentos que no habían sido considerados antes material de archivo ni por su tipo (post-its, tweets, mensajes en Facebook, etc.) ni por su finalidad (además de registrar decisiones o actuaciones, expresan ideas y sentimientos).

La mayoría de los documentos son electrónicos y procedentes de redes sociales como Facebook, Twitter, YouTube o Instagram. La ubicuidad de estas plataformas y su facilidad de uso las ha convertido en medios excelentes para que todas las personas puedan documentar y compartir el testimonio de su existencia. Estos nuevos materiales tienen retos de tratamiento que impactan directamente en la metodología archivística.
En el 11M, 17A y \#cuéntalo los archiveros documentan esas manifestaciones ciudadanas, asumiendo un activismo archivístico que no es ajeno a su implicación política y social en la comunidad 
A pesar de la heterogeneidad de los soportes a la que hemos aludido e incluso del carácter efímero de muchos de ellos, hablamos de documentos de archivo porque están unidos por una misma procedencia. Lo que otorga sentido y valor a cada pieza es su pertenencia al conjunto y el contexto en el que se ha producido. Así por ejemplo, un post-it recogido en el Memorial de la Rambla no tiene ningún valor separado del conjunto. La manifestación de indignación de un único tweet tiene un valor individual pero no colectivo, es el conjunto de tweets interrelacionados, que mantienen los metadatos de contexto, los que le otorgan ese valor añadido.

Dichos documentos tienen las características propias de los documentos de archivo. Se han gestado de forma natural a consecuencia de una actividad social, son originales y únicos y son evidencia y testimonio de una acción o un sentimiento. Así pues, se puede determinar su autenticidad, fiabilidad e integridad. Cuando el archivado es simultáneo, o muy cercano en el tiempo al proceso de creación, se puede documentar la trazabilidad y la custodia ininterrumpida. También la existencia de los metadatos en los documentos es un instrumento poderoso para el mantenimiento de la información de contexto y, por tanto, de verificación de su autenticidad. Por ejemplo, en el Memorial de la Rambla, los archiveros han documentado y contextualizado el proceso de captura y archivado lo que permite seguir la traza de los documentos desde el espacio de memoria hasta su custodia.

Es cierto que la presencia masiva de documentos electrónicos provenientes de las redes sociales conlleva problemas de identificación de documentos auténticos y de tratamiento. Por ejemplo, en el caso del 1-O hubo muchos bulos

"fundamentados en la exageración de los hechos, la manipulación de las imágenes, la suplantación de identidades y la utilización de fotografías y vídeos procedentes de otros contextos" (Aparici; García-Marín; Rincón-Manzano, 2019, p. 13)

Ello plantea preguntas que la ciencia archivística deberá responder:

- ¿Debemos conservar todos los tweets, aunque sean de bulos?

- ¿Debemos hacer una selección? Si es así,

- ¿En base a qué criterios?

- ¿Quién decide?

- ¿Cómo se detectan los tweets generados por bots o por las llamadas "granjas de troles"?

- ¿De quién es la responsabilidad de analizar la fiabilidad de la información? ¿De archiveros, historiadores, periodistas?

Aún es temprano para tener respuestas definitivas a estas preguntas. Pero sí es interesante al respecto analizar la estrategia de la $A A C-G D$ para la conservación de esos fondos que se basa en el uso de la metodología archivística para garantizar la formación de fondos confiables. Su proyecto \#arxivemelmoment pretende conservar sólo los documentos aportados por los ciudadanos de los que se puede demostrar la trazabilidad y autenticidad.

Otra estrategia seguida es la de \#Cuéntalo, que implica guardar los tweets de unos hashtags determinados en unos días determinados. El proyecto archivístico se asegura de conservar los tweets junto con todos sus metadatos para poder analizar su trazabilidad y su autenticidad. De lo que no hay ninguna duda es de la necesidad de contar con equipos multidisciplinares para su tratamiento que involucren a archiveros, informáticos y analistas de datos.

\section{4. ¿Quién custodia los fondos?}

Flinn y Stevens (2009) argumentan que los archivos de la comunidad comparten dos características:

- los productores tienen la voluntad de ser independientes en la toma de decisiones sobre la conformación del fondo;

- crean sus propios archivos porque piensan que las organizaciones que se ocupan del patrimonio no son receptivas a sus inquietudes e intereses.

Por esta razón, al menos durante un tiempo, los creadores se resisten a depositarlos en instituciones oficiales, al temer que no se les conceda suficiente visibilidad. Esta situación la acredita el Archivo 15M, que permanece fiel a sus principios fundacionales y es autogestionado por voluntarios. Como explicábamos, las proposiciones institucionales para su conservación fueron rechazadas, ante la desconfianza de que no tuviera la suficiente visibilidad y difusión.

Respecto a \#Cuéntalo, el proyecto se encuentra en proceso. Los otros tres casos están liderados por instituciones. Los documentos del Referéndum 1-O, han sido depositados y permanecen en archivos comarcales y municipales de toda Cataluña y son de acceso abierto. Los materiales que generó la reacción cívica a los atentados del 17A se encuentran en el $A M C B$ y son de libre acceso y su tratamiento técnico está financiado por la empresa multinacional española Telefónica. El Archivo del Duelo es hoy en día una colección del Archivo Histórico Ferroviario de la Fundación de los Ferrocarriles Españoles de Madrid; es el único caso donde los fondos no son de libre acceso y es necesario justificar el interés de la consulta para obtener así una autorización.
El movimiento $15 \mathrm{M}$ rechazó la oferta de los archivos institucionales para conservar sus fondos ante la desconfianza de que no tuviera la suficiente visibilidad y difusión 
En todos estos proyectos las tecnologías tienen un papel crucial para dar voz a las comunidades que tradicionalmente han estado infrarrepresentadas en los archivos. Los nuevos medios necesitan instrumentos tecnológicos adecuados para su preservación. Plataformas online como Documenting the now proporcionan medios para ayudar a crear datasets para uso de los investigadores sociales y para preservar el contenido digital. La plataforma empezó su andadura en 2014 en Estados Unidos, como un proyecto colaborativo entre universidades y la ayuda económica de la Andrew W. Mellon Foundation. Desarrolla herramientas archivísticas con el objetivo de capturar y conservar contenido digital de las redes sociales de acontecimientos especialmente significativos y a demanda de colectivos académicos, estudiantes y archiveros, entre otros.

https://www.docnow.io

También Internet Archive, a partir de Wayback Machine, se ha posicionado como un sistema poderoso para conservar documentación que de otro modo no se conservaría, como ilustran los casos estudiados.

\section{Conclusiones}

En el artículo se han analizado cinco importantes experiencias de archivado de movimientos sociales y manifestaciones ciudadanas espontáneas de nuestro pasado reciente. Las características y particularidades de estos archivos nos han permitido reflexionar sobre algunas implicaciones que estos fondos plantean en relación con la teoría y la práctica archivística.

Constatamos que la ciudadanía es consciente de la importancia histórica de sus acciones y quiere dejar su testimonio documental. Esta entiende que los documentos proveen de evidencias y pruebas que contribuyen a explicar sucesos y entender el mundo en el que vive. Por eso se reivindica como sujeto archivístico y productor de archivos que documenten los movimientos sociales con voz propia. La formación del archivo forma parte de la movilización política y social; la acción de archivado empodera a la ciudadanía porque le permite expresarse, evitar el olvido de los acontecimientos y su manipulación; es un instrumento de denuncia e incluso de transformación social.

Hemos argumentado por qué la documentación generada constituye un fondo de archivo. En cada caso se puede identificar un productor colectivo, no necesariamente organizado, que tiene un propósito social (denuncia, duelo) y una voluntad de conservar sus documentos. Además, el fondo se ha gestado de forma natural en el transcurso de las actividades de los productores. La composición de los fondos es muy diversa y reúne tipos poco representados en los archivos tradicionales, pero no cabe duda de que son documentos de archivo por su vinculación con el contexto de producción.

Tradicionalmente las instituciones archivísticas no han sido receptivas a estos fondos, percibidos como conjuntos de documentos que no tienen las características típicas de los documentos de archivo. No obstante, en los casos estudiados se ha comprobado la implicación del colectivo profesional y un cierto activismo archivístico porque en la formación de algunos de los fondos han intervenido archiveros e instituciones archivísticas.

Por consiguiente, consideramos que las instituciones archivísticas no pueden ignorar los fondos como los aquí descritos. Según la Declaración universal sobre los archivos de 2010 (ICA, 2010), estos juegan un papel esencial en el desarrollo de la sociedad contribuyendo a la constitución y salvaguarda de la memoria individual y colectiva. Así pues, la responsabilidad del archivo como institución es conservar una memoria lo más plural posible. Por ende, conviene recordar que tienen el mandato legal de conservar el patrimonio documental y ofrecer un espacio seguro y de confianza para la custodia indefinida de los documentos. No dejamos de apreciar que las soluciones de archivo autónomo propuestas en algunos de los casos descritos son inestables. En este sentido, la experiencia y herramientas que pueden aportar los archivos en el tratamiento de los fondos es fundamental para su gestión y preservación a largo plazo.

Es cierto también que los archivos, al asumir esta nueva línea de trabajo deberán abordar cuestiones teóricas, metodológicas y técnicas complejas, entre las cuáles podemos citar:

- definición de los criterios de evaluación para determinar qué se conserva;

- aplicación del principio de procedencia y la ampliación del concepto de productor;

- esquemas de metadatos;

- métodos y protocolos para verificar la autenticidad, fiabilidad e integridad de los datos, así como para documentar la trazabilidad de la información;

- preservación digital a largo plazo.

Para afrontar estos retos y del mismo modo que sucede en otros ámbitos, es imprescindible la colaboración de equipos interdisciplinares. La gestión y el archivado eficiente de los documentos digitales sólo puede abordarse con la colaboración de archiveros, analistas de datos e informáticos, entre otros profesionales. Pero además es imprescindible hacer partícipes a los ciudadanos de muchas de estas decisiones, en especial la elección de lo que debe conservarse.

La aproximación a la ciudadanía, que tradicionalmente ha percibido a los archivos como instituciones lejanas, inescrutables y ajenas a la mayoría de las personas, puede abrir un diálogo fecundo y beneficioso para todas las partes: 
- a los ciudadanos, porque aumentaría su conocimiento sobre lo que los archivos pueden ofrecerles e incrementaría la confianza hacia ellos, como espacios de memoria y como entes de confianza;

- a los archivos, les daría mayor visibilidad y prestigio y contribuiría a su sostenibilidad;

- favorecería a la misma ciencia archivística al alumbrar debates que abren vías de renovación en la disciplina.

En síntesis, puede parecer que los archivos de la comunidad cuestionan el concepto de neutralidad de los archivos. Pero en realidad confirman que estos han sido y son producto de su época y del espacio donde están insertados. Configurar una memoria plural es básico en una sociedad democrática, puesto que permite un relato múltiple de los acontecimientos. En este reto, no menor, deben estar implicados ciudadanos, archivos y administraciones públicas.

\section{Notas}

1. Entendemos como movimiento social

"un grupo de personas o agente colectivo con unos objetivos comunes y solidaridad cuyas acciones dirigidas a alcanzar dichos objetivos tienen una continuidad en el tiempo y un carácter de desafío colectivo al orden existente" (López-Martínez, 2004, v. 2. pp 736).

Los movimientos sociales a pesar de ser muy diversos entre sí comparten tres características:

- constituyen redes sociales de individuos heterogéneos;

- se encuentran en una situación de conflicto y plantean unas exigencias a los gobernantes;

- tienen continuidad en el tiempo.

\section{Referencias}

\#Catmemoria (2017). Catalunya 1 octubre 2017: memòria gràfica geolocalitzada d'un dia que mai oblidarem. https://catmemoria.cat

AAC-GD (2017). Arxivar l'avui per guanyar el futur: com preservar el testimoni de l'\#1oct. Barcelona: Associació d’Arxivers-Gestors de Documents de Catalunya.

https://arxivers.com/campanyes/arxivar-lavui-per-guardar-el-futur

Ajuntament de Barcelona (2017). Memorial la Rambla 17: Barcelona Ciutat de Pau. Barcelona: L'Ajuntament. https://www.barcelona.cat/memorialrambla17a/ca

Alberch-Fugueras, Ramon (2000). “Archiveros sin Fronteras”. El profesional de la información, v. 9, n. 9, pp. 20-23. http://www.elprofesionaldelainformacion.com/contenidos/2000/septiembre/4.pdf

Antich, Xavier (2011). “Del 'mal d'arxiu' a la 'febre d'arxiu': la noció d’arxiu en la cultura contemporània”. Lligall: revista catalana d'arxivística, n. 32, pp. 12-41.

Aparici, Roberto; García-Marín, David; Rincón-Manzano, Laura (2019). “Noticias falsas, bulos y trending topics. Anatomía y estrategias de la desinformación en el conflicto catalán”. El profesional de la información, v. 28, n. 3, pp.1-16. https://doi.org/10.3145/epi.2019.may.13

Archivo 15M (2014). “Importante: no basura, carteles, pancartas, archivo”. En: VI Jornada técnica documentación, política y activismo.

https://archivosol15m.wordpress.com/2014/11/24/importante-no-basura-carteles-pancartas-archivo-texto-de-laponencia-que-se-leyo-en-la-vi-jornada-tecnica-documentacion-politica-y-activismo-21112014

Archivo 15M (2015). “Importante: no basura, carteles, pancartas, archivo”. Tábula: revista de archivos de Castilla-León, n. 18, pp. 137-147.

Archivo 15M (2018). [Blog del] Archivo 15 M. Madrid.

https://archivosol15m.wordpress.com/about

Archivo 15M (2019). "Bibliografía y biblioteca digital sobre el 15M elaboradas por el archivo15m". Archivo 15M, 11 diciembre.

https://archivosol15m.wordpress.com/2019/12/11/bibliografia-y-biblioteca-digital-sobre-el-15-m-elaboradas-porarchivo15m

Arxiu Nacional de Catalunya (2017). Ayúdanos a conservar la \#memòria1oct. Generalitat de Catalunya.

http://anc.gencat.cat/es/detall/noticia/Ajundans-a-conservar-la-memoria1oct

Bastian, Jeannette-Allis; Alexander, Ben (eds.) (2009). Community archives: the shaping of memory. London: Facet. ISBN: 9781856046398

Blanco-Rivera, Joel A. (2009). "Truth commissions and the construction of collective memory: the Chile experience". In: Bastian, Jeannette-Allis; Alexander, Ben (eds.). Community archives: the shaping of memory. London: Facet, pp. 133-147. ISBN: 9781856046398

https://doi.org/10.29085/9781856049047.010 
Cea, Antonio; Díaz-Mas, Paloma; Martínez, Pilar; Ortiz, Carmen; Sánchez-Carretero, Cristina (2011). “En torno a la documentación de los conflictos: el caso del Archivo del Duelo". Tábula: revista de archivos de Castilla-León, n. 14, pp. 11-23.

Cook, Terry (2010). "Panorama del pasado: archiveros, historiadores y combates por la memoria”. Tábula: revista de archivos de Castilla-León, n. 13, pp. 153-166.

Cook, Terry (2013). "Evidence, memory, identity, and community: four shifting archival paradigms". Archival science, v. 13, n. 2-3, pp. 95-120.

https://doi.org/10.1007/s10502-012-9180-7

Corominas-Noguera, Mariona (2005). "Arxivers sense fronteres, una aposta per la solidaritat arxivística internacional". Revista d'arxius, n. 4-5, pp. 445-454.

Corradini, Luisa (2006). "Los intelectuales del mundo y La nación. No hay que confundir memoria con historia, dijo Pierre Nora: la visión del filósofo y académico francés”. Entrevista a Pierre Nora. La nación, 15 marzo.

https://www.lanacion.com.ar/788817-no-hay-que-confundir-memoria-con-historia-dijo-pierre-nora

Criado-Boada, Felipe (2005). “Apertura: presentación del Archivo del duelo”. En: I Jornadas archivo y memoria 2005 : archivos etnográficos y construcción social de la memoria: 8 y 9 de abril de 2005. Madrid: Fundación de los Ferrocarriles Españoles; CSIC.

http://www.docutren.com/archivoymemoria/ArchivoyMemoria2005/pdf/1J_Presentaci\%C3\%B3n_Archivo_Duelo.pdf

Derrida, Jacques (1997). Mal de archivo: una impresión freudiana. Madrid: Trotta. ISBN: 8481641332

Douglas, Jennifer (2017). "Origins and beyond: The ongoing evolution of archival ideas about provenance”. In: MacNeil, Heather; Eastwood, Terry (eds.). Currents of archival thinking, $2^{\text {nd }}$ ed. Santa Barbara (California): ABC-CLIO, pp. $25-52$. ISBN: 9781440839085

Eastwood, Terry (2017). "A contested realm: The nature of archives and the orientation of archival science". In: MacNeil, Heather; Eastwood, Terry (eds.). Currents of archival thinking, $2^{\text {nd }}$ ed. Santa Barbara (California): ABC-CLIO, pp. 3-23. ISBN: 9781440839085

Evans, Joanne; McKemmish, Sue; Daniels, Elizabeth; McCarthy, Gavan (2015). "Self-determination and archival autonomy: advocating activism". Archival science, v. 15, n. 4, pp. 337-368.

https://doi.org/10.1007/s10502-015-9244-6

Flinn, Andrew (2007). "Community histories, community archives: some opportunities and challenges". Journal of Society of Archivists, v. 28, n. 2, pp. 151-176.

https://doi.org/10.1080/00379810701611936

Flinn, Andrew; Stevens, Mary (2009). "'It is noh mistri, wi mekin histri'. Telling our own story: independent and community archives in the UK, challenging and subverting the mainstream". In: Bastian, Jeanette-Allis; Alexander, Ben (eds.). Community archives: the shaping of memory. London: Facet, pp. 3-27. ISBN: 9781856046398 https://doi.org/10.29085/9781856049047.003

Flinn, Andrew; Stevens, Mary; Shepherd, Elizabeth (2009). "Whose memories, whose archives? Independent community archives, autonomy and the mainstream". Archival science, v. 9, n. 1-2, pp. 71-86.

https://doi.org/10.1007/s10502-009-9105-2

Gilliland, Anne; McKemmish, Sue; Lau, Andrew J. (eds.) (2016). Research in the archival multiverse. Clayton: Victoria Monash University Publishing. ISBN: 9781876924676

https://doi.org/10.26530/oapen_628143

Giraldo, Marta-Lucía (2019). Archivos vivos: documentar los derechos humanos y la memoria colectiva en Colombia. Tesis doctoral. Universidad Autónoma de Barcelona. Departamento de Historia Moderna y Contemporánea.

Harris, Verne (2002). "The archival sliver: power, memory, and archives in South Africa”. Archival science, v. 2, n. 1-2, pp. 63-86.

https://doi.org/10.1007/BF02435631

Harris, Verne (2011). “Archons, aliens and angels: power and politics in the archive". In: Hill, Jennie (ed.). The future of archives and recordkeeping. London: Facet, pp. 103-122. ISBN 978185609666 https://doi.org/10.29085/9781856048675.007

Hurley, Chris (2005a). "Parallel provenance: Part 1: What, if anything, is archival description?". Archives \& manuscripts, v. 33, n. 1, pp. 110-145.

Hurley, Chris (2005b). "Parallel provenance: Part 2: When something is not related to everything else". Archives \& manuscripts, v. 33, n. 2, pp. 52-91. 
ICA (2000). ISAD (G). Norma internacional general de descripción arxivística. Adoptada por el Comité de Normas de Descripción, Estocolmo, Suecia, 19-22 Septiembre 1999. Madrid: Consejo Internacional de Archivos.

ICA (2010). Declaración universal sobre los archivos. International Council on Archives.

https://www.ica.org/sites/default/files/UDA_June2012_press_SP.pdf

ICA (2019). Records in contexts: A conceptual model for archival description. Consultation draft v. 0.2 (preview). International Council on Archives. Experts Group on Archival Description, December.

https://www.ica.org/sites/default/files/ric-cm-0.2_preview.pdf

Kelly, Glen (2009). "The single Noongar claim: native title, archival records and an original community in Western Australia". In: Bastian, Jeanette-Allis; Alexander, Ben (eds.). Community archives: the shaping of memory. London: Facet, pp. 49-64. ISBN: 9781856046398

Ketelaar, Eric (2001). "Tacit narratives: the meanings of archives". Archival science, v. 1, n. 2, pp. 131-141. https://doi.org/10.1007/BF02435644

Ketelaar, Eric (2012). "Cultivating archives: meanings and identities". Archival science, v. 12, n. 1, pp. 19-33. https://doi.org/10.1007/s10502-011-9142-5

López-Martínez, Mario (ed.) (2004). Enciclopedia de paz y conflictos. 2 v. Editorial Universidad de Granada. ISBN: 84 33830953

Martínez, Pilar (2011). "La colección documental y bibliográfica del Archivo del duelo: creación, conservación y descripción”. En: Sánchez-Carretero, Cristina (coord.). El Archivo del duelo: análisis de la respuesta ciudadana ante los atentados del 11 de marzo en Madrid. Madrid: Consejo Superior de Investigaciones Científicas, pp. 69-79. ISBN: 9788400092870

Matas-Balaguer, Josep (1999). “La identificació d’un fons: tot escoltant Marco Polo i Khublai Khan darrere una cortina estant". Lligall: revista catalana d'arxivística, n. 15, pp. 11-46.

Millán, Agustín (2018). “\#Cuéntalo, un espacio virtual contra la violencia machista”. Diario16, 14 diciembre. https://diario16.com/cuentalo-espacio-virtual-la-violencia-machista

Nesmith, Tom (2006). "The concept of societal provenance and records of nineteenth-century aboriginal-European relations in Western Canada: Implications for archival theory and practice". Archival science, v. 6, n. 3/4, pp. 351-360. https://doi.org/10.1007/s10502-007-9043-9

Nora, Pierre (1984). Les lieux de mémoire. Paris: Gallimard. ISBN: 2070701921

Ricoeur, Paul (2004). La memoria, la historia, el olvido. México, etc.: Fondo de Cultura Económica. ISBN: 9505575963

Ruiz-Gómez, Vicenç (2019). "Professional associations and the shift from archival activism to designing social archives". Blog International Council on Archives, 24 July.

https://blog-ica.org/2019/07/24/professional-associations-and-the-shift-from-archival-activism-to-designing-social-archives

Ruiz-Gómez, Vicenç; Maria-Vallès, Aniol (2018). “\#Cuéntalo: preservació, tractament i pluralització d’un fons documental social". La DaDA: el diari digital de l'Associació d'Arxivers i Gestors de Documents de Catalunya, 25 julio.

https://arxivers.com/ladada/reportatge-cuentalo-preservacio-tractament-i-pluralitzacio-dun-fons-documental-social

Ruiz-Gómez, Vicenç; Maria-Vallès, Aniol; Summers, Ed (2017). Catalan referendum tweets. https://archive.org/details/catalan-tweet-ids

Senante, Alberto (2012). "Archivo 15M, la memoria de un sueño". Asturias mundial, 28 marzo. https://www.asturiasmundial.com/noticia/20963/archivo-15m-memoria-sueno

Upward, Frank (1996). "Structuring the records continuum part one: postcustodial principles and properties". Archives \& manuscripts, v. 24, n. 2, pp. 268-285.

https://publications.archivists.org.au/index.php/asa/article/view/8583

Valdés, Isabel (2018). "Los 14 días en los que 150.00 mujeres no se callaron". El país, 13 diciembre. https://elpais.com/sociedad/2018/12/12/actualidad/1544617022_492358.html

Wakimoto, Diana K.; Bruce, Christine; Partridge, Helen (2013). "Archivist as activist: lessons from three queer community archives in California". Archival science, v. 13, n. 4, pp. 293-316.

https://doi.org/10.1007/s10502-013-9201-1

Yeo, Geoffrey (2017). "Continuing debates about description". In: MacNeil, Heather; Eastwood, Terry (eds.). Currents of archival thinking, $2^{\text {nd }}$ ed. Santa Barbara (California): ABC-CLIO, pp. 163-192. ISBN: 9781440839085 